\title{
Cardiac Arrhythmias after Subarachnoid Hemorrhage: Risk Factors and Impact on Outcome
}

\author{
Jennifer A. Frontera ${ }^{a}$ Augusto Parra ${ }^{c, d}$ Daichi Shimbo ${ }^{e}$ Andres Fernandez $^{c}$ \\ J. Michael Schmidt ${ }^{c}$ Patricia Peter ${ }^{c}$ Jan Claassen ${ }^{c}$ Katja E. Wartenberg ${ }^{c}$ \\ Fred Rincon $^{c}$ Neeraj Badjatial ${ }^{c, d}$ Andrew Naidech ${ }^{b}$ E. Sander Connolly ${ }^{d}$ \\ Stephan A. Mayer ${ }^{c, d}$ \\ ${ }^{a}$ Neurological Intensive Care Unit, Departments of Neurosurgery and Neurology, Mount Sinai School of Medicine, \\ ${ }^{b}$ Departments of Neurology and Neurosurgery, Northwestern University, Departments of ${ }^{\mathrm{C}}$ Neurology, \\ ${ }^{\mathrm{d}}$ Neurosurgery, and ${ }^{\mathrm{e}}$ Medicine, Columbia University College of Physicians and Surgeons, New York, N.Y., USA
}

\section{Key Words}

Arrhythmia, risk factors $\cdot$ Atrial fibrillation $\cdot$ Subarachnoid hemorrhage $\cdot$ Outcome predictors

\begin{abstract}
Objective: Serious cardiac arrhythmias have been described in approximately $5 \%$ of patients after subarachnoid hemorrhage $(\mathrm{SAH})$. The aim of this study was to identify the frequency, risk factors and clinical impact of cardiac arrhythmia after SAH. Methods: We prospectively studied 580 spontaneous SAH patients and identified risk factors and complications associated with the development of clinically significant arrhythmia. Multiple logistic regression analysis was used to calculate adjusted odds ratios for the effect of arrhythmia on hospital complications and 3-month outcome, as measured by the modified Rankin Scale, after controlling for age, neurological grade, APACHE-2 physiologic subscore, brain herniation and aneurysm size. Results: Arrhythmia occurred in $4.3 \%(n=25)$ of patients. Atrial fibrillation and flutter were the most common arrhythmias, occurring in $76 \%$ $(n=19)$ of these patients. Admission predictors of cardiac arrhythmia included older age, history of arrhythmia and ab-
\end{abstract}

\section{KARGER}

(c) 2008 S. Karger AG, Basel

Fax +4161306 1234

E-Mail karger@karger.ch

www.karger.com normal admission electrocardiogram (all $p<0.05$ ). After adjusting for length of stay, hospital complications associated with arrhythmia included myocardial ischemia, hyperglycemia, and herniation (all $p<0.05$ ). Arrhythmia was associated with an excess ICU stay of 5 days $(p=0.002)$. After adjusting for other predictors of outcome, arrhythmia was associated with an increased risk of death (adjusted OR 8.0, 95\% confidence interval 1.9-34.0, $p=0.005$ ), and death or severe disability (adjusted OR 6.9, 95\% confidence interval 1.5-32.0, $p=0.014)$. Conclusions: Clinically important arrhythmias, most often atrial fibrillation or flutter, occurred in $4 \%$ of SAH patients. Arrhythmias are associated with an increased risk of cardiovascular comorbidity, prolonged hospital stay and poor outcome or death after SAH, after adjusting for other predictors of poor outcome.

Copyright $\odot 2008$ S. Karger AG, Basel

\section{Introduction}

Cardiac abnormalities following subarachnoid hemorrhage (SAH) are well described. Electrocardiogram (ECG) changes, including $\mathrm{P}$ wave abnormalities, pro-

\footnotetext{
Jennifer A. Frontera

Mount Sinai School of Medicine, Department of Neurosurgery

One Gustave L. Levy Place, Box 1135, New York, NY 10029 (USA)

Tel. +1 212241 9512, Fax +1 2124100603
}

E-Mail Jennifer.Frontera@mountsinai.org 
longed QTc interval, ST segment and T-wave changes, occur in over $50 \%$ of patients [1-3], often in the first few days after $\mathrm{SAH}$ onset, and are associated with poor neurologic grade on admission [4].

Between 50 and $100 \%$ of patients experience cardiac rhythm disturbances during the acute phase of SAH. The majority of these abnormalities are benign, with sinus tachycardia, sinus bradycardia, and premature atrial and ventricular beats being the most common. Only 1-4\% of patients experience a clinically significant arrhythmia, such as ventricular tachycardia or atrial tachyarrhythmias [5-10]. Predictors of serious cardiac arrhythmias remain poorly defined, and their impact on clinical outcome is unknown. In this study we sought to identify the prevalence, risk factors, hospital complications associated with arrhythmia and impact on long-term outcome of cardiac arrhythmias after SAH. We hypothesized that, though uncommon, clinically significant arrhythmias are associated with increased hospital complications, prolonged length of stay and worse outcome.

\section{Methods}

\section{Patient Population}

The Columbia University SAH Outcomes Project prospectively enrolled 580 consecutive patients with spontaneous SAH admitted to the Neurologic Intensive Care Unit between July 1, 1996 and May 1, 2002. The diagnosis of SAH was established on the basis of admission computed tomography (CT) or by xanthochromia of the cerebrospinal fluid. Both aneurysmal and non-aneurysmal cases of spontaneous SAH were included in this analysis. Exclusion criteria included: secondary SAH from trauma, arteriovenous malformation or other causes; age $<18$ years; admission $>14$ days after SAH onset, or no ECG available for review.

\section{Clinical Management}

The management of SAH patients at our institution has been described in detail previously $[11,12]$. Phenytoin was administered for a median of 7 days and levels were checked regularly to maintain a serum concentration between 10 and $20 \mathrm{mg} / \mathrm{dl}$ [13]. All patients received $0.9 \%$ normal saline at $1 \mathrm{mg} / \mathrm{kg} / \mathrm{h}$ and supplemental $5 \%$ albumen was administered as needed to maintain normovolemia (central venous pressure $5-8 \mathrm{~mm} \mathrm{Hg}$ ). Patients who developed symptomatic vasospasm, defined as neurologic deterioration not explained by other causes, were treated with vasopressors (either phenylephrine or norepinephrine) to maintain a systolic blood pressure between 160 and $220 \mathrm{~mm} \mathrm{Hg}$, adjusted to clinical response.

Clinical and Radiographic Assessment

Admission clinical status was evaluated with the Hunt-Hess scale and the Acute Physiology and Chronic Health Evaluation (APACHE)-2 physiologic subscore (calculated by subtracted Glasgow Coma Score from the APACHE-2 score). We defined hy- potension as a systolic blood pressure $\leq 90 \mathrm{~mm} \mathrm{Hg}$, pulmonary edema was defined as the presence of characteristic radiographic infiltrates in the setting of hypoxia, and we considered myocardial infarction/ischemia (MI) to be evidence of cardiac injury (based on ECG, troponin and echocardiographic data judged not to be secondary to neurogenic injury by a study team of physicians in weekly conference). We examined medications, procedures, elevated volume status (defined by central venous pressure $\geq 8 \mathrm{~mm}$ $\mathrm{Hg}$, and $\geq 1$ liter net volume intake in $24 \mathrm{~h}$ prior to arrhythmia onset) and electrolyte levels within $24 \mathrm{~h}$ of arrhythmia onset. Abnormal values were defined by our laboratory's lower limit of normal, including a potassium $<3.6 \mathrm{mg} / \mathrm{dl}$, magnesium $<1.5 \mathrm{mg} / \mathrm{dl}$, phosphorus $<2.5 \mathrm{mg} / \mathrm{dl}$ and calcium $<8.4 \mathrm{mg} / \mathrm{dl}$ or ionized calcium $<1.12 \mathrm{mg} / \mathrm{dl}$. An abnormal troponin level was defined as $>0.2 \mathrm{ng} / \mathrm{ml}$. Total phenytoin levels within $24 \mathrm{~h}$ of development of arrhythmia were recorded, as were average phenytoin levels over the course of hospitalization.

\section{Cardiac Monitoring}

All patients underwent continuous cardiac rhythm monitoring while in the neuro-ICU. ECGs were routinely obtained at admission and then periodically, as determined by the treating physician. Serial troponin levels and echocardiography were performed when ECGs were abnormal, in patients with a prior history of cardiac disease, or in the setting of cardiovascular symptoms such as chest pain, hypotension, or pulmonary edema. Ejection fraction (EF) was assessed by transthoracic (and/or transesophageal) echocardiography, and was dichotomized as normal $(\mathrm{EF} \geq 50 \%$ ) versus abnormal.

\section{Blinded Cardiac Assessment}

Serial ECGs for all patients coded with arrhythmia by the treating physician were independently assessed by a board-certified cardiologist (DS), blinded to the clinical characteristics and outcome status of the patient. Patients coded as experiencing an arrhythmia, but who did not have ECGs available for review, were excluded from the present analysis. Admission ECGs and all follow up ECGs were assessed. We defined clinically significant arrhythmia as any rhythm disturbance other than sinus tachycardia, sinus bradycardia, or sinus rhythm with premature atrial or ventricular complexes.

\section{Outcome Measures}

Survival and functional outcome was assessed at 3 months using the modified Rankin Scale (mRS; 0 = full recovery, 6 = death); poor outcome was defined as severe disability or death (mRS score 4-6). Median excess ICU and hospital length of stay (LOS) were calculated by comparing the median LOS of patients with arrhythmia to those without.

\section{Statistical Analysis}

Continuous variables were dichotomized based on clinical cut-points or median values. The association of arrhythmia with candidate demographic and clinical variables was assessed in a univariate analysis using binary logistic regression. Variables found to be significant on univariate analysis were then entered by hand into a multiple logistic regression model based on clinical relevance of each variable. A multivariate model addressing the association of arrhythmia and in-hospital complications was constructed, adjusting for hospital LOS. Finally, a multivariate mod- 
el examining the effect of arrhythmia on 3-month outcome was created, after controlling for other predictors of outcome including age, Hunt-Hess grade, aneurysm size, herniation and APACHE-2 physiologic subscore [11, 14]. Elevated intracranial pressure and low EF did not predict outcome on univariate analysis and were not included in the multivariate model. The variable for clinically significant arrhythmias was added individually to this model to calculate adjusted odds ratios for the strength of association of arrhythmia with 'death' and 'severe disability or death' (mRS 4-6). Tests for interactions were performed for all significant variables in the multivariable models. Significance was set at $\mathrm{p}<0.05$ for all analyses.

\section{Results}

Of 580 SAH patients enrolled in our database, $8 \%$ (n = 46) were coded as having an arrhythmia sometime during their hospital stay. Ten patients did not have ECGs available for review. After excluding patients with sinus bradycardia, sinus tachycardia or sinus rhythm with or without premature ventricular or apical complexes, $4.3 \%$ $(n=25)$ of patients in the cohort had a verified clinically significant arrhythmia. Among this group the mean age was 53 years (range 20-89), and 68\% were female. The majority of patients underwent aneurysm clipping (81\%). The type of aneurysm repair (surgical clipping vs. endovascular coiling) was not associated with an increased risk of arrhythmia. The median number of different arrhythmias per patient was 1 (range 1-4) and the median number of days of arrhythmia per patient was 2.5 (range 1-41). Arrhythmia developed a median of 3 days after SAH onset (range 0-30). The most common type of arrhythmia was atrial fibrillation or flutter (76\%) and only $16 \%$ of patients experienced a ventricular arrhythmia (table 1).

Admission predictors for arrhythmia were examined (table 2). An abnormal ECG (such as left or right axis deviation, PR segment abnormality, ST segment elevation or depression, T-wave abnormality, QTc prolongation or bundle branch block) at admission was found in $92 \%$ of patients who developed an arrhythmia and independently predicted arrhythmia [adjusted OR 9.4, 95\% confidence interval (CI) 2.2-40.5, p =0.002]. On the cardiologist's review of admission ECGs among arrhythmia patients, a prolonged QTc $>500$ ms was seen in $16 \%$ of patients, ST segment abnormalities were seen in $67 \%$ and T-wave inversion was seen in $25 \%$. Though a cardiac history of coronary artery disease, angina or MI were associated with the development of a clinically significant arrhythmia during hospitalization on univariate analysis, only a history of arrhythmia remained an independent
Table 1. Types of arrhythmia among 25 patients with SAH

\begin{tabular}{lrr}
\hline Type of arrhythmia & $\mathrm{n}$ & $\%$ \\
\hline Atrial fibrillation or atrial flutter & 19 & 76 \\
Junctional rhythm & 4 & 16 \\
Pauses & 4 & 16 \\
Supraventricular tachycardia & 3 & 12 \\
Asystole & 3 & 12 \\
Bigeminy & 2 & 8 \\
Ectopic atrial pacemaker & 1 & 4 \\
Multifocal atrial tachycardia & 1 & 4 \\
Non-sustained ventricular tachycardia & 1 & 4 \\
Sustained ventricular tachycardia & 1 & 4 \\
2nd degree heart block Mobitz I & 1 & 4 \\
2nd degree heart block Mobitz II & 1 & 4 \\
3rd degree heart block & 1 & 4 \\
Torsade de pointes & 0 & 0 \\
Ventricular fibrillation & 0 & 0 \\
\hline
\end{tabular}

predictor on multivariate analysis (adjusted OR 9.1, 95\% CI $2.7-30.7, \mathrm{p}<0.001)$. All 5 patients $(20 \%)$ with a history of arrhythmia had atrial fibrillation in the past, but 2 of these 5 developed other arrhythmias including atrial flutter, second degree heart block and junctional rhythm.

Clinical treatments associated with the development of arrhythmia were recorded. Among those with arrhythmia, $24 \%$ received hypertensive, hypervolemia therapy (HHT) to treat symptomatic vasospasm, $48 \%$ received an intravenous pressor and $4 \%$ received hypertonic saline prior to the time the arrhythmia developed. Twenty percent of patients with arrhythmia were in volume overload at the time of arrhythmia onset (table 3). There was no significant association between the development of arrhythmia and HHT. Mean phenytoin levels were not significantly associated with arrhythmia. The most common electrolyte abnormality was hypokalemia, which occurred in $28 \%$ of arrhythmia patients. An elevated troponin or CK-MB occurred in $24 \%$ of patients.

Recurrent arrhythmia occurred in $72 \%$ of our cohort. Despite treatment, $44 \%$ continued to have arrhythmias. The most common arrhythmias to recur were atrial fibrillation or flutter (56\%) and ventricular arrhythmias (11\%). Treatments included digoxin in 10 patients (40\%), diltiazem in 7 patients (28\%), metoprolol in 4 patients (16\%), amiodarone in 4 patients (16\%), procainamide in 1 patient (4\%), lidocaine in 1 patient (4\%) and atropine in 1 patient (4\%).

Several medical complications were significantly associated with arrhythmia after adjusting for hospital 
Table 2. Admission risk factors for arrhythmia among SAH patients

\begin{tabular}{|c|c|c|c|c|c|c|}
\hline & \multicolumn{2}{|c|}{$\begin{array}{l}\text { Entire cohort } \\
(\mathrm{n}=580)\end{array}$} & \multicolumn{2}{|c|}{$\begin{array}{l}\text { Arrhythmia group } \\
(\mathrm{n}=25)\end{array}$} & \multirow[t]{2}{*}{ OR (95\% CI) } & \multirow[t]{2}{*}{$\mathrm{p}$} \\
\hline & $\mathrm{n}$ & $\%$ & $\mathrm{n}$ & $\%$ & & \\
\hline \multicolumn{7}{|l|}{ Demographics } \\
\hline Age $>53$ years & 300 & 52 & 21 & 84 & $5.1(1.7-15.2)$ & $0.003^{*}$ \\
\hline Gender (female) & 392 & 68 & 19 & 76 & $1.5(0.6-3.9)$ & 0.374 \\
\hline Race (non-white) & 284 & 49 & 6 & 24 & $0.3(0.1-0.8)$ & 0.015 \\
\hline \multicolumn{7}{|l|}{ Medical history } \\
\hline Hypertension & 266 & 46 & 19 & 76 & $5.5(1.8-16.4)$ & 0.002 \\
\hline Coronary artery disease/angina & 31 & 5 & 3 & 12 & $3.5(1.0-12.9)$ & 0.057 \\
\hline Arrhythmia & 18 & 3 & 4 & 16 & $9.1(2.7-30.7)$ & $<0.001^{*}$ \\
\hline $\mathrm{CHF}$ & 12 & 2 & 1 & 4 & $2.7(0.3-22.3)$ & 0.351 \\
\hline Myocardial infarction & 22 & 4 & 3 & 12 & $4.9(1.3-18.4)$ & 0.017 \\
\hline Thyroid dysfunction & 32 & 6 & 1 & 4 & $0.9(0.1-7.2)$ & 0.946 \\
\hline \multicolumn{7}{|l|}{ Admission radiographic data } \\
\hline SAH sum score $\geq 15$ & 225 & 38 & 20 & 80 & $5.0(1.7-14.8)$ & 0.004 \\
\hline IVH present & 281 & 49 & 19 & 76 & $3.9(1.4-10.5)$ & 0.008 \\
\hline $\mathrm{ICH}$ present & 96 & 17 & 5 & 20 & $1.3(0.5-3.5)$ & 0.650 \\
\hline Aneurysm size $\geq 10 \mathrm{~mm}$ & 117 & 20 & 8 & 32 & $2.2(0.9-5.4)$ & 0.093 \\
\hline \multicolumn{7}{|l|}{ Admission clinical data } \\
\hline Hunt-Hess score & 337 & 58 & 19 & 76 & $1.4(1.0-1.9)$ & 0.033 \\
\hline Loss of consciousness & 224 & 39 & 16 & 64 & $4.3(1.7-11.2)$ & 0.003 \\
\hline Seizure at ictus & 5 & 9 & 9 & 16 & $2.4(0.8-7.4)$ & 0.132 \\
\hline APACHE- 2 subscore $\geq 5$ & 303 & 52 & 18 & 72 & $2.6(1.0-6.8)$ & 0.045 \\
\hline Abnormal admission ECG & 320 & 55 & 23 & 92 & $9.4(2.2-40.5)$ & $0.002^{*}$ \\
\hline
\end{tabular}

* p value significant on multivariate analysis. $\mathrm{CHF}=$ Congestive heart failure; $\mathrm{IVH}=$ intraventricular hemorrhage; $\mathrm{ICH}=$ intracerebral hemorrhage.

LOS, these included hyperglycemia, brainstem compression from herniation and MI (table 4). Of those who developed MI, the mean troponin level was $9.2 \mathrm{ng} / \mathrm{ml}$ (range $0-22.2 \mathrm{ng} / \mathrm{ml})$. Three patients with MI had normal transthoracic echocardiography and 3 had mild to moderate reductions in EF with anterior-septal or septal hypokinesis. A transthoracic or transesophageal echocardiogram was performed in $38 \%$ of the entire cohort and in $76 \%$ of those who developed an arrhythmia. Of those who underwent echocardiography, an $\mathrm{EF}<50 \%$ was seen in $21 \%$ of the entire cohort and in $11 \%$ of those who developed an arrhythmia. There was no significant association between an EF $<50 \%$ and arrhythmia (OR 0.4, $95 \%$ CI $0.1-1.9, \mathrm{p}=0.265)$. Similarly, $\mathrm{EF}<50 \%$ was not a significant predictor of outcome. Four of the 25 arrhythmia patients (16\%) experienced a cardiac arrest at some point during their hospitalization. Though none of the patients who arrested died in the hospital, 3 (75\%) were dead at 3 months and 1 was severely disabled. No patients with arrhythmia experienced renal failure and there was no significant association of arrhythmia with blood stream infection or sepsis. The only neurologic complication associated with arrhythmia was herniation (table 4).

Sixteen of 25 (64\%) patients who experienced an arrhythmia were dead at 3 months and 1 was severely disabled. Of all patients with arrhythmia who died, 50\% died of direct effects of the initial SAH, $17 \%$ died of medical complications (including arrhythmia), 17\% died of cerebral edema, $8 \%$ died of rebleeding, and $8 \%$ died of various other causes. After controlling for age, HuntHess grade, clinical herniation, aneurysm size, and APACHE-2 physiologic subscore, clinically significant arrhythmias remained independently predictive of death (adjusted OR 8.0, 95\% CI 1.9-34.0, $\mathrm{p}=0.005$ ) and severe disability or death (mRS 4-6; adjusted OR 6.9, 95\% CI 
Table 3. Hospital risk factors among arrhythmia cohort

\begin{tabular}{lrr}
\hline & $\mathrm{n}$ & $\%$ \\
\hline Medications & & \\
$\quad$ Intravenous pressor & 12 & 48 \\
$\quad$ Hypertonic saline & 1 & 4 \\
$\quad$ Elevated total phenytoin level $>20 \mathrm{mg} / \mathrm{dl}$ & 1 & 4 \\
$\quad$ Diuretic & 6 & 24 \\
$\quad$ Albuterol & 4 & 16 \\
$\quad$ Nicotine patch & 1 & 4 \\
Electrolyte and lab abnormalities & 7 & 28 \\
$\quad$ Potassium $<3.6$ mg/dl & 4 & 16 \\
$\quad$ Phosphorus $<2.5 \mathrm{mg} / \mathrm{dl}$ & 0 & 0 \\
$\quad$ Magnesium $<1.5 \mathrm{mg} / \mathrm{dl}$ & & \\
$\quad$ Calcium $<8.4 \mathrm{mg} / \mathrm{dl}$ or & 4 & 16 \\
$\quad$ ionized calcium $<1.12 \mathrm{mg} / \mathrm{dl}$ & 6 & 24 \\
$\quad$ Elevated troponin or CK-MB & & \\
Volume status & 8 & 32 \\
$\quad$ Central venous pressure $\geq 8 \mathrm{~mm}$ Hg & 6 & 24 \\
$\quad>1$ liter net volume input in previous $24 \mathrm{~h}$ & & \\
Procedures/therapies & 9 & 36 \\
$\quad$ Central line & 2 & 8 \\
$\quad$ Pulmonary artery catheter & 0 & 0 \\
$\quad$ Therapeutic hypothermia & & \\
\hline
\end{tabular}

1.5-32.0, $\mathrm{p}=0.014$ ) at 3 months (table 5). We examined the effect of subtypes of arrhythmia (i.e. atrial or ventricular arrhythmias) on outcome, but did not find any significant associations.

A significantly longer ICU LOS was associated with the occurrence of a clinically significant arrhythmia. The median ICU LOS in those with arrhythmia was 13 days, compared to 8 days in the patients without arrhythmia $(\mathrm{p}=0.002)$; the median hospital LOS in those with arrhythmia was 15 days, compared to 13 days in the patients without arrhythmia $(\mathrm{p}=0.132)$.

\section{Discussion}

In this inception cohort study we were able to demonstrate that arrhythmia following SAH is associated with a high rate of mortality and predicts poor functional outcome at 3 months, after adjusting for neurological grade and severity of clinical illness (APACHE-2 physiological subscore), age, herniation and aneurysm size. Our study is the first, to our knowledge, to show that clinically sig-

Table 4. Hospital complications associated with arrhythmia, adjusted for hospital length of stay

\begin{tabular}{|c|c|c|c|c|c|c|}
\hline & \multicolumn{2}{|c|}{ Entire cohort } & \multicolumn{2}{|c|}{ Arrhythmia group } & \multirow{2}{*}{$\begin{array}{l}\text { Adjusted OR } \\
(95 \% \mathrm{CI})\end{array}$} & \multirow{2}{*}{$\begin{array}{l}\text { Adjusted } \\
\mathrm{p}\end{array}$} \\
\hline & $\mathrm{n}$ & $\%$ & $\mathrm{n}$ & $\%$ & & \\
\hline \multicolumn{7}{|l|}{ Medical complication } \\
\hline Ejection fraction $<50 \%$ & 46 & 8 & 3 & 12 & $0.4(0.1-1.9)$ & 0.285 \\
\hline Cardiac arrest & 57 & 10 & 4 & 16 & $2.0(0.6-6.0)$ & 0.238 \\
\hline Blood stream infection & 48 & 8 & 3 & 12 & $1.4(0.4-4.8)$ & 0.639 \\
\hline Hypotension $^{\mathrm{a}}$ & 105 & 18 & 8 & 32 & $2.2(0.9-5.2)$ & 0.082 \\
\hline Anemia requiring transfusion & 209 & 36 & 14 & 56 & $2.1(0.9-5.1)$ & 0.099 \\
\hline Fever $>38.3^{\circ} \mathrm{C}$ & 310 & 54 & 19 & 76 & $2.4(0.8-6.8)$ & 0.089 \\
\hline DVT & 23 & 4 & 2 & 8 & $1.7(0.4-7.9)$ & 0.502 \\
\hline Hyperglycemia $>11.1 \mathrm{mmol} / \mathrm{l}$ & 174 & 30 & 13 & 52 & $2.7(1.2-6.1)$ & $0.020^{*}$ \\
\hline MI/Ischemia & 35 & 6 & 7 & 28 & $6.7(2.6-17.4)$ & $<0.001^{*}$ \\
\hline Pulmonary edema & 82 & 14 & 7 & 28 & $2.2(0.8-5.6)$ & 0.110 \\
\hline \multicolumn{7}{|l|}{ Neurologic complication } \\
\hline Symptomatic vasospasm & 95 & 16 & 7 & 28 & $1.7(0.7-4.3)$ & 0.269 \\
\hline Herniation & 89 & 15 & 8 & 32 & $3.4(1.4-8.3)$ & $0.008^{*}$ \\
\hline Cerebral infarction & 208 & 36 & 11 & 44 & $1.2(0.5-2.9)$ & 0.610 \\
\hline Seizures & 31 & 5 & 2 & 8 & $1.3(0.3-6.0)$ & 0.726 \\
\hline Aneurysm rebleed & 58 & 10 & 1 & 8 & $0.8(0.2-3.4)$ & 0.732 \\
\hline
\end{tabular}


Table 5. Adjusted outcomes at 3 months among SAH patients with clinically significant arrhythmia

\begin{tabular}{|c|c|c|c|c|c|c|}
\hline \multirow[t]{2}{*}{ Outcome at 3 months } & \multicolumn{2}{|c|}{ Entire cohort } & \multicolumn{2}{|c|}{ Arrhythmia group } & \multirow{2}{*}{$\begin{array}{l}\text { Adjusted OR } \\
(95 \% \mathrm{CI})\end{array}$} & \multirow{2}{*}{$\begin{array}{l}\text { Adjusted } \\
\mathrm{p}\end{array}$} \\
\hline & $\mathrm{n}$ & $\%$ & $\mathrm{n}$ & $\%$ & & \\
\hline Dead (mRS 6) & 119 & 21 & 16 & 64 & $8.0(1.9-34.0)$ & $0.005^{*}$ \\
\hline Severely disabled or dead (mRS 4-6) & 151 & 26 & 17 & 68 & $6.9(1.5-32.0)$ & $0.014^{*}$ \\
\hline
\end{tabular}

Outcome adjusted for age, Hunt-Hess grade, aneurysm size, APACHE-2 physiologic subscore and brain herniation. mRS = Modified Rankin Scale.

${ }^{*}$ p value significant on multivariate analysis.

nificant arrhythmias are predictive of mortality as well as disability after SAH. Previous studies have yielded conflicting results regarding the clinical importance of various cardiac abnormalities after SAH. Tachyarrhythmias and cardiac ischemia have been related to poor outcome after $\mathrm{SAH}$, though this association was less robust after controlling for admission Glasgow Coma Scale score and Fisher grade [1]. While ECG abnormalities were found to predict outcome in another study, this association lost significance when a multivariate model was applied [15]. Similarly, others have not been able to find a significant relationship between ECG abnormalities and outcome after $\mathrm{SAH}$, after controlling for established predictors of poor outcome $[4,16]$. Elevated troponin was independently predictive of death or severe disability at 14 days after SAH in one study, but this effect was lost at 3 months [17]. Though $50 \%$ of patients who died succumbed to the direct effects of the initial bleeding, $17 \%$ died of medical complications, including arrhythmia.

Though some studies have described rates of arrhythmia after SAH of 30\% and higher, these studies included patients with sinus bradycardia and tachycardia and premature atrial and ventricular complexes $[4,6]$. The rates of clinically significant arrhythmia, as defined in this paper, are similar to those seen in the literature. We observed a higher rate of atrial fibrillation and flutter than has been previously described in other SAH arrhythmia cohorts. While $76 \%$ of our group developed atrial fibrillation or flutter, this rhythm was observed in only $10 \%$ of SAH patients with arrhythmia in another study [5]. In mixed ICU populations, clinically significant tachyarrhythmias occur in up to $20 \%$ of patients overall, with atrial fibrillation occurring most frequently [18]. In our study, recurrent arrhythmias (particularly atrial fibrillation or flutter) were common despite treatment, suggest- ing that more aggressive management of arrhythmia may be warranted.

Predictors for the development of arrhythmia in our cohort included older age, abnormal ECG at admission and a history of arrhythmia. Though worse neurological grade and APACHE-2 physiologic subscores were significant risk factors for the development of arrhythmia on univariate analysis, this effect was not sustained on multivariate analysis. Arrhythmia does not merely reflect degree of critical illness. Pre-existing cardiac disease was not independently associated with arrhythmia, suggesting that a history of cardiac disease alone does not explain a predisposition to arrhythmia. Risk factors for tachyarrhythmias amongst critically ill surgical ICU patients include sepsis, elevated CVP, acute renal failure, anemia requiring transfusion and poor APACHE-2 scores [18-20]. We were unable to find any of these associations in our neurologically ill SAH patients [19].

Neurologically ill patients differ from general critically ill patients in several ways. Elevated catecholamine levels and hypothalamic dysfunction have been described in SAH patients compared with controls and have been associated with both ECG abnormalities and tachyarrhythmias [21-23]. Hyperglycemia, which can occur in response to an acute catecholamine surge or generalized stress response following neurologic injury was noted to be associated with arrhythmia in our cohort $[14,24,25]$. Some arrhythmias may be related, in part, to HHT therapy used to treat symptomatic vasospasm, as both intravenous pressors and volume expansion, which are known risk factors for supraventricular tachyarrhythmias, were used frequently in the patients who developed arrhythmia. We were unable to detect a significant relationship between HHT and arrhythmia, but this may be due to insufficient power. Though elevated phenytoin levels can 
be associated with arrhythmia, we did not observe this association in our cohort.

Interestingly, arrhythmia was significantly associated with brainstem compression from herniation. Increased ICP and physical compression of brainstem and hypothalamic autonomic centers in herniating patients can trigger catecholamine responses that could instigate an arrhythmia.

The ICU LOS was significantly prolonged in patients who developed arrhythmia compared to the rest of the cohort. Though it is not possible to determine whether prolonged LOS predisposed patients to arrhythmia or if arrhythmia itself was causal, the fiscal implications of prolonged LOS are profound.

There are severallimitations to this study which should be mentioned. First, we only had echocardiographic data in $38 \%$ of our cohort. However, no other studies, to our knowledge, have examined $\mathrm{EF}$ and the occurrence of arrhythmia after $\mathrm{SAH}$; as such, we are the first to explore this relationship. We did not have complete time-locked data on IV pressor or hypertonic saline use in the cohort as a whole, and this limited our ability to compare the effects of these medications in those with arrhythmia and those without. We also did not have complete data on troponin levels.

In summary, although clinically significant arrhythmias are relatively uncommon after $\mathrm{SAH}$, they are associated with a high mortality rate, and serious cardiac and neurological comorbidity. Older patients with a history of arrhythmia or an abnormal ECG on admission should undergo close cardiac monitoring, and the presence of rhythm disturbances should prompt aggressive measures to treat MI, maintain a normal cardiac rhythm and minimize autonomic stress, when present.

\section{Acknowledgements}

This work was supported by a grant-in-aid from the American Heart Association (to S.A.M.) \#9750432N, and grants HL072866 and HL076857 from the National Institutes of Health (to D.S).

\section{References}

${ }_{1}$ Brouwers PJ, Wijdicks EF, Hasan D, Vermeulen M, Wever EF, Frericks H, van Gijn J: Serial electrocardiographic recording in aneurysmal subarachnoid hemorrhage. Stroke 1989;20:1162-1167.

-2 Mayer SA, LiMandri G, Sherman D, Lennihan L, Fink ME, Solomon RA, DiTullio M, Klebanoff LM, Beckford AR, Homma S: Electrocardiographic markers of abnormal left ventricular wall motion in acute subarachnoid hemorrhage. J Neurosurg 1995; 83:889-896.

3 Salvati M, Cosentino F, Artico M, Ferrari M Franchi D, Domenicucci M, Ramundo Orlando E, Tacconi L, Cosentino F Jr: Electrocardiographic changes in subarachnoid hemorrhage secondary to cerebral aneurysm. Report of 70 cases. Ital J Neurol Sci 1992;13:409-413.

-4 Sakr YL, Lim N, Amaral AC, Ghosn I, Carvalho FB, Renard M, Vincent JL: Relation of ECG changes to neurological outcome in patients with aneurysmal subarachnoid hemorrhage. Int J Cardiol 2004;96:369-373.

$\checkmark 5$ Di Pasquale G, Pinelli G, Andreoli A, Manini G, Grazi P, Tognetti F: Holter detection of cardiac arrhythmias in intracranial subarachnoid hemorrhage. Am J Cardiol 1987; 59:596-600.
6 Andreoli A, di Pasquale G, Pinelli G, Grazi $\mathrm{P}$, Tognetti F, Testa C: Subarachnoid hemorrhage: frequency and severity of cardiac arrhythmias. A survey of 70 cases studied in the acute phase. Stroke 1987;18:558-564.

7 Estanol Vidal B, Badui Dergal E, Cesarman E, Marin San Martin O, Loyo M, Vargas Lugo B, Perez Ortega R: Cardiac arrhythmias associated with subarachnoid hemorrhage: prospective study. Neurosurgery 1979;5:675-680.

$>8$ Estanol BV, Marin OS: Cardiac arrhythmias and sudden death in subarachnoid hemorrhage. Stroke 1975;6:382-386.

9 Estanol BV, Loyo MV, Mateos JH, Foyo E, Cornejo A, Guevara J: Cardiac arrhythmias in experimental subarachnoid hemorrhage. Stroke 1977;8:440-449.

10 Solenski NJ, Haley EC Jr, Kassell NF, Kongable G, Germanson T, Truskowski L, Torner JC: Medical complications of aneurysmal subarachnoid hemorrhage: a report of the multicenter, cooperative aneurysm study. Participants of the Multicenter Cooperative Aneurysm Study. Crit Care Med 1995;23: 1007-1017.

11 Claassen J, Bernardini GL, Kreiter K, Bates J, Du YE, Copeland D, Connolly ES, Mayer SA: Effect of cisternal and ventricular blood on risk of delayed cerebral ischemia after subarachnoid hemorrhage: the Fisher scale revisited. Stroke 2001;32:2012-2020.
12 Wartenberg KE, Schmidt JM, Claassen J, Temes RE, Frontera JA, Ostapkovich N, Parra A, Connolly ES, Mayer SA: Impact of medical complications on outcome after subarachnoid hemorrhage. Crit Care Med 2006; 34:617-623; quiz 624.

13 Naidech AM, Kreiter KT, Janjua N, Ostapkovich N, Parra A, Commichau C, Connolly ES, Mayer SA, Fitzsimmons BF: Phenytoin exposure is associated with functional and cognitive disability after subarachnoid hemorrhage. Stroke 2005;36:583-587.

14 Frontera JA, Fernandez A, Claassen J, Schmidt M, Schumacher HC, Wartenberg K, Temes R, Parra A, Ostapkovich ND, Mayer SA: Hyperglycemia after SAH: predictors, associated complications, and impact on outcome. Stroke 2006;37:199-203.

15 Schuiling WJ, Algra A, de Weerd AW, Leemans P, Rinkel GJ: ECG abnormalities in predicting secondary cerebral ischemia after subarachnoid haemorrhage. Acta Neurochir (Wien) 2006;148:853-858; discussion 858.

16 Zaroff JG, Rordorf GA, Newell JB, Ogilvy CS, Levinson JR: Cardiac outcome in patients with subarachnoid hemorrhage and electrocardiographic abnormalities. Neurosurgery 1999;44:34-39; discussion 39-40. 
17 Naidech AM, Kreiter KT, Janjua N, Ostapkovich ND, Parra A, Commichau C, Fitzsimmons BF, Connolly ES, Mayer SA: Cardiac troponin elevation, cardiovascular morbidity, and outcome after subarachnoid hemorrhage. Circulation 2005;112:2851-2856.

18 Reinelt P, Karth GD, Geppert A, Heinz G: Incidence and type of cardiac arrhythmias in critically ill patients: a single center experience in a medical-cardiological ICU. Intensive Care Med 2001;27:1466-1473.

19 Goodman S, Shirov T, Weissman C: Supraventricular arrhythmias in intensive care unit patients: short and long-term consequences. Anesth Analg 2007;104:880-886.
20 Seguin P, Signouret T, Laviolle B, Branger B, Malledant Y: Incidence and risk factors of atrial fibrillation in a surgical intensive care unit. Crit Care Med 2004;32:722-726.

21 Sakr YL, Ghosn I, Vincent JL: Cardiac manifestations after subarachnoid hemorrhage: a systematic review of the literature. Prog Cardiovasc Dis 2002;45:67-80.

22 Kawahara E, Ikeda S, Miyahara Y, Kohno S: Role of autonomic nervous dysfunction in electrocardio-graphic abnormalities and cardiac injury in patients with acute subarachnoid hemorrhage. Circ J 2003;67:753756.
23 Cruickshank JM, Neil-Dwyer G, Stott AW: Possible role of catecholamines, corticosteroids, and potassium in production of electrocardiographic abnormalities associated with subarachnoid haemorrhage. Br Heart J 1974;36:697-706.

24 Allport LE, Butcher KS, Baird TA, MacGregor L, Desmond PM, Tress BM, Colman $\mathrm{P}, \mathrm{Davis}$ SM: Insular cortical ischemia is independently associated with acute stress hyperglycemia. Stroke 2004;35:1886-1891.

25 Capes SE, Hunt D, Malmberg K, Pathak P, Gerstein HC: Stress hyperglycemia and prognosis of stroke in nondiabetic and diabetic patients: a systematic overview. Stroke 2001;32:2426-2432. 